\title{
Evaluation and analysis of traffic noise along bus rapid transit system corridor
}

\author{
${ }^{1 * R . ~ K . ~ M i s h r a, ~}{ }^{2}$ M. Parida, ${ }^{3}$ S. Rangnekar \\ ${ }^{1}$ Center for Transportation Systems, Indian Institute of Technology Roorkee -247 667, India \\ ${ }^{2}$ Civil Engineering Department and Associated Faculty, Center for Transportation Systems, Indian Institute of \\ Technology Roorkee -247 667, India \\ ${ }^{3}$ Department of Management Studies, Indian Institute of Technology, Roorkee -247 667, India \\ Received 27 May 2010; $\quad$ revised 18 June 2010; accepted 24 July 2010; available online 1 September 2010
}

\begin{abstract}
Due to increasing motorization, construction of flyovers and growth in transport network, the noise level has exceeded the prescribed limits in many Indian cities. The health implications of high noise levels are being identified as hypertension, sleeplessness, mental stress, etc. Due to this adverse effect of noise level, it is essential to assess the impact of traffic noise on residents and road users. This research is an effort to quantify and analyze the traffic noise emissions along bus rapid transit corridor in Delhi. Field measurements were carried out to understand and assess various aspects of the impact of bus rapid transit system corridor on land use and social lives of residents and road users. The present analysis presents the comparison between observed and predicted noise level at selected corridors and also describes the mitigatory measures to overcome such type of traffic noise pollution through design of noise barrier along the road and motivate people towards the use of public transport system.
\end{abstract}

Keywords: Central pollution control board ; Federal highway administration traffic;Human health, Prediction error, Traffic noise

\section{INTRODUCTION}

Currently all the developing countries like India are facing threat due to vehicular noise pollution. Migration of people from rural to urban areas, expansion of cities, infrastructure development, population growth and urbanization are important factors resulting in motorization and consequent increase in levels of various urban pollution (Banerjee, 2008; Duran and Gonzalez, 2009; Mohammadi Roozbahani et al., 2009; Omidvari and Nouri, 2009). The total urban population of India has increased considerably over the past three decades, rising from 109 million in 1971 to 160 million in 1981 and then 217 million in 1991 and 285 million in 2001 (Office of the Registrar, 2001; Padam, 2001). This increase in population coupled with the increase in number of motor vehicles is showing alarming levels of traffic congestion, air pollution, and noise pollution and road accidents. Urban traffic noise is one of the most critical types of noise and normally considered more interfering than the other types of noises

凶*Corresponding Author Email: rajeevmishraiitr@gmail.com Tel.: +133 2286 305; Fax: +133 2273560
(Unweltbundesamt, 2000; Zannin et al., 2003). The impact of traffic noise variations on urban roads of Hong Kong has assumed alarming populations. It is high time that all the factors contributing to the traffic noise are taken into consideration. On the basis of survey data, probability distribution for each of the key factor is derived and reliability analysis of traffic noise is estimated (William and Tam, 1998). Johnson and Saunders (1968) built up a model based on the conjecture that all motor vehicles are uniformly spaced and are generating the same maximum noise. They proposed a technique to predict the statistical mean sound level $\mathrm{L}_{50}$ due to freely flowing traffic. They explained that in case of higher traffic the noise level decreases by $3 \mathrm{~dB}$ per doubling of distance. A technique relating the noise levels produced by traffic to the nuisance caused to people living the neighborhood. They used traffic noise index to predict the nuisance likely to be produced by a given intensity of traffic and conferred the methods for reducing this nuisance to an acceptable low figure (Langdon and 
Scholes, 1968). Scholes and Sargent (1971) discussed about some factors to be considered in setting standards for traffic noise and have extended discussion of possible units for depicting traffic noise levels to include the noise pollution level. Nelson and Godfrey (1974) studied the road traffic noise in rural environment. During their study they measured the traffic noise alongside 26 miles of the A66 within the Lake District National Park and in the towns of Keswick and Coker mouth and they built a $50 \mathrm{~dB}(\mathrm{~A}) \mathrm{L}_{10}$ contour for road traffic noise. A noise model for free flowing traffic had been proposed by Baranek and Newman. They illustrated that propagation loss varies from 3$4.5 \mathrm{~dB}$ per doubling of distance depending on the ground cover (Beranek and Newman, 1976). The road vehicles had been categorized to measure the road traffic noise. Measurements of speed, noise level and vehicles had made in road conditions ranging from fairly congested urban situations with speeds around $20 \mathrm{kmph}$ to free flow on motorways with speeds over $100 \mathrm{kmph}$. They used these measurements to construct approximate vehicle noise levels and speed characteristics over the speed range $20-100 \mathrm{kmph}$ for up to 6 vehicle categories and used as input in the TRRL computer model of traffic noise (Nelson and Piner, 1977). Samuels and Thomas (1978) learned the measurement and analysis of road noise. During their study they measured the roadside noise levels as a vehicle passes by test track under various conditions of speed, load and engine operation and so on. Gupta (1979) tried to develop relationship between the vehicular noise and stream flow parameters. They built up a relationship between the vehicular noise and stream flow parameters.

$L_{10}=18.092433+19.90357 \times \log _{10}(Q w)$

Where, $Q w=$ traffic volume in EPCU* $/ h$

In India, the different classes of vehicles use the common roadway facilities without segregation on the highway, traffic volume becomes heterogeneous, and hence it is required to convert all the categories of vehicles into a single unit called equivalent passenger car units (EPCU).

Gupta et al., (1986) carried out their study about road traffic noise for different land uses for mixed traffic flow in Roorkee at different selected locations. In their study, they computed L10, L50, L90, Leq and noise pollution levels. The road traffic noise problems of residential scientist apartments near a busy highway intersection in Delhi had been assessed. The noise level at all the seven floors was observed to be higher than permissible levels of $65 \mathrm{~dB}$ (A) as per Indian Standards (Sarin et al., 1990). The noise level had been monitored at different selected junctions to measure the overall environmental noise problem in Ramagundam. During the study, L10, L50, L90 and Leqhad been recorded. On the basis of these values, the TNI and LNP had been calculated and analyzed (Yognarayana and Ramalingeswara, 1994). Kumar Vimal (1997) learned the urban noise scenario in Delhi and developed different traffic parameters like traffic volume, traffic speed and distance from pavement edge and the equivalent sound level Leq. From the developed correlations, it is possible to envisage the impact of traffic developments in terms of noise pollution if future and timely measures for control can be implemented (Gupta et al. 1986). For silence zone, the developed equation is:

$L_{e q}(1 h)=47.45+8.58 \times \log (Q w)-0.14 d d B(A)$

Where:

$Q w=$ traffic volume in $E P C U / h$

A highway noise model for Indian conditions was proposed by Bhattacharya, Jain, Parida and others. Noise study was carried out at $169 \mathrm{~km}$ on NH-58 and 42 $\mathrm{km}$ on $\mathrm{NH}-2$. Individual vehicle noise differs with speed, so individual vehicle noise levels over a wide range of speeds were taken. On the basis of their study individual noise level equations were derived at for bituminous and cement concrete surface separately (Bhattacharya et al., 2001). Sheikh Shahid Saleem (2002) performed his study on NH-58 and developed a noise prediction model for Indian traffic conditions by collecting various data like traffic flow rate, traffic speed, gradient, percentage of heavy vehicles and road surface. A traffic noise model was developed for the highways in Thailand. This study developed a new basic noise level $\left(\mathrm{L}_{0}\right)$ for vehicle types and conditions in Thailand. From $\mathrm{L}_{0}$ of the six new vehicle groups like automobile, light-truck, heavy truck, semi-trailer and full-trailer, bus and motorcycles, a model was formulated to improve the forecasting efficiency by applying an adjustment factor (Pamanikabud and Vivitjinda, 2002). From the previous study, it is concluded that traffic noise caused by nearly saturated traffic flow conditions on the main roads in Beijing is significant and exceeding national standards by $5.2 \mathrm{dBA}$. Traffic noise index and 
noise pollution level strongly supported the negative influence of traffic noise on the urban population in the city (Bengang et al., 2002). Jetti, (2003) studied the performance assessment of noise prediction model. During his study, he collected data related to ambient noise level, classified traffic volume, classified traffic speed and highway geometrics from different selected location in Delhi. By putting these values in federal highway administration traffic noise model (FHWA TNM) he determined the relative prediction efficiency of this model. A survey was conducted in the city of Florianopolis (Southern Brazil) to determine the characteristics of noise levels as related to road traffic volume and composition. The effect of traffic composition on road noise was studied in a survey. On the basis of survey and analysis, it is concluded that the most commonly used noise levels in road noise emission evaluation like L10 and Leq can be estimated by knowing the traffic composition with reasonably good accuracy (Joel et al., 2004). An exposure-effect relationship was estimated between the level of road traffic noise at the most exposed side of a dwelling's facade and the resident's reaction to road traffic noise. From the analysis it is found that the Norwegians tend to react stronger to road traffic noise than predicted from the most recent international compilation of international socio-acoustic surveys (Klæboe et al., 2004). Previously a relationship between urban noise level and its components like transport noise and background noise was established (Lebiedowska, 2005). Banerjee et al. (2009) computed the temporal and spatial distribution of road traffic induced noise pollution in an urban environment by monitoring and mapping. Thirty five locations were selected for the study in Asanol City of West Bengal, India. From the study, it was found that the population was exposed to significantly high noise level, which was caused mostly due to road traffic. Vulnerable establishments like schools and hospitals were subjected to significantly high noise level throughout the day.

A number of researchers have integrated urban noise modeling with geographic information techniques in Asian cities. Pamanikabud and Tansatcha (2003) integrated traffic noise with visualization package TNoise GIS. Their study explored the utilization of a geographical information system for the analysis and forecasting of highway traffic noise. They developed a GIS system that can be applied effectively to analyze traffic noise levels generated by uninterrupted or free flow traffic conditions based on the popular traffic noise models: the US's FHWA and the UK's CORTN. This study also developed the technique for estimation of path length difference that affected by the box barrier on receiver points outside that barrier, by projecting the coordinates of the box barrier on to the perpendicular line from the receiver points to the roadway. Also, this GIS-based program is concerned with the errors that occur from all models for calculating noise levels along the back edges of barriers parallel to the roadway. The utilization of an interpolation technique in this system can eliminate this error and give the effective noise level estimation. This makes the calculation of insertion loss of noise barriers more accurate and realistic. Chung et al. (2007) developed a DRONE software tool by the integration of the dynamic output from a traffic simulation model with the noise estimation model to evaluate road traffic noise in a large area with the consideration of network dynamic traffic flow and the buildings. Unit noise data base had been generated by the application of this tool in Tsukuba City of Japan and used for testing different traffic management scenarios on the study area. A geographical information system based noise simulation model has been developed to generate noise level in Versova of Mumbai, India. During their study, they calibrated GIS based noise simulation with observed noise levels during day and night time. On the basis of their study, they concluded that the noise barrier and green belt can be designed to check the propagation of the noise due to traffic, industry and any new development and construction activities (Sharma et al., 2010). Tang and Wang (2007) integrated a road traffic noise model, an operational air pollution model, digital maps, an urban landscape model and a geographic information system (GIS). During this study, they developed a prototype system for modeling noise and air pollution in Macao Peninsula. Four urban forms with different land -use patterns and urban geometries had been considered. The assessment of street environment in each urban form had been done in terms of the modeled noise and air pollution in front of individual buildings located in the area of the urban form. Bengang et al. (2002) developed an integrated noise-GIS system to provide general functions for noise modeling and an additional tool for noise design in China. Using this system, suggestions had been given to improve the efficiency and accuracy of traffic noise assessment and noise design. Jha et al. (2009) 
developed a GIS-based noise analysis model for highway noise analysis due to vehicular traffic by integrating FHWA's traffic noise model TNM methodology and a GIS. This model was capable of being integrated to a highway alignment optimization model. A socio-acoustic survey of community response to road traffic noise was conducted in Hanoi and Ho Chi Minh City. During the study the annoyance responses of European people were compared with that of the Vietnamese people. From the comparison it is found that the Vietnamese people were less annoyed by road traffic noise by about $5 \mathrm{dBA}$. From the survey analysis it is also concluded that Hanoi respondents were more annoyed by noise than Ho Chi Minh City respondents (Phan et al., 2010).

Delhi has primarily road based transportation network. Due to lack of road space, there is hardly any space for further expansion of road network and still the total number of vehicles is increasing ontinuously in Delhi. The result is alarmingly high noise levels at sensitive locations of the capital city. Traffic noise becomes a major cause for irritation and concern for communities living in the vicinity of major road corridors. In view of the rapid vehicular growth in urban areas, it is necessary to study traffic noise with respect to causative factors.

The aim of BRT system is to provide dedicated right of way to buses and simultaneously safeguarding cyclists and pedestrians by encouraging lane driving on engineered road spaces along large and wide corridors and link them to metros and other colony roads for easy access. Besides giving priority to buses, the system also provides dedicated lanes for pedestrians and non-motorized vehicles like cycles and rickshaws etc. BRT system is part of the Multi Modal Transport Policy of GNCTD (Government of National Capital Territory of India). Now a days, in highly urbanized capital city like Delhi, the increased number of vehicles on the road has not only reduced the mobility of a large section of people but also increased the pollution level, journey time and average per $\mathrm{km}$ fuel consumption. Delhi has introduced a new concept of public transport system i.e. Bus rapid transit system (BRTS), promoting segregated lane for movement of buses. Total of 7 BRT corridors are proposed to be built in the first phase while another 26 corridors covering a total length of $310 \mathrm{~km}$ are proposed to be built by the year 2020. Fig. 1 depicts the complete network of Bus Rapid Transit System in Delhi. This will be in addition to more than
$400 \mathrm{~km}$ of metro train coverage by 2020 and further coverage by Monorail and Light Rail. The traffic volume on the BRT corridor is very high. The corridor is situated along some of the prime colonies in South Delhi. More than 1.35 million vehicles cross the junction in a day (16 h). Due to high volume vehicular traffic, noise pollution has become a serious problem along the BRTS corridor. This study is based on analysis of that noise originated from those vehicles. Table 1 indicates the detailed features about the BRTS. noise analysis along the corridor in Delhi. The emphasis is on the newly introduced bus rapid transit system corridor. The paper includes interpretation of primary data to predict the noise levels along the BRTS corridor. It focuses on comparative study of modelled and measured noise levels. In addition, the paper also discusses about the impact of this corridor on land use and socio-economic aspects of lives of residents and road users living along this corridor. The paper recommends mitigating measures like design of noise barrier for stretches where the noise level exceeds the standards set by the Central Pollution Control Board (CPCB).

\section{MATERIALS AND METHODS}

Data Collection

BRTS Corridor of Panchsheel Enclave, South Delhi, has been selected for the study. The site represents predominantly residential land use pattern. During field study, various data like traffic volume, noise levels, spot speed and geometrical parameters have been collected. Fig. 2 and 3 showing the hourly variation of traffic volume in both side of BRTS corridor. Vehicle count and vehicle classification were carried out manually at the site for a period of $12 \mathrm{~h}$. The noise levels were recorded in $\mathrm{dB}$ (A) using noise level meters. Measurements were recorded every $15 \mathrm{~s}$ for a period of $15 \mathrm{~min} / \mathrm{h}$. This was considered to represent the variations in noise levels of the entire hour. The spot speeds were recorded for all categories of vehicles by using radar gun. A large number of speeds were recorded per vehicle during the entire span of the day to accurately estimate the average speeds of each vehicle category.

Table 1: Various phases of BRTS corridors in Delhi

\begin{tabular}{lcc}
\hline Phase & Corridors & Length $(\mathrm{km})$ \\
\hline I (2005-2010) & 7 & 115.5 \\
II (2010-2015) & 3 & 28.0 \\
III (2015-2020) & 3 & 166.0 \\
\hline
\end{tabular}




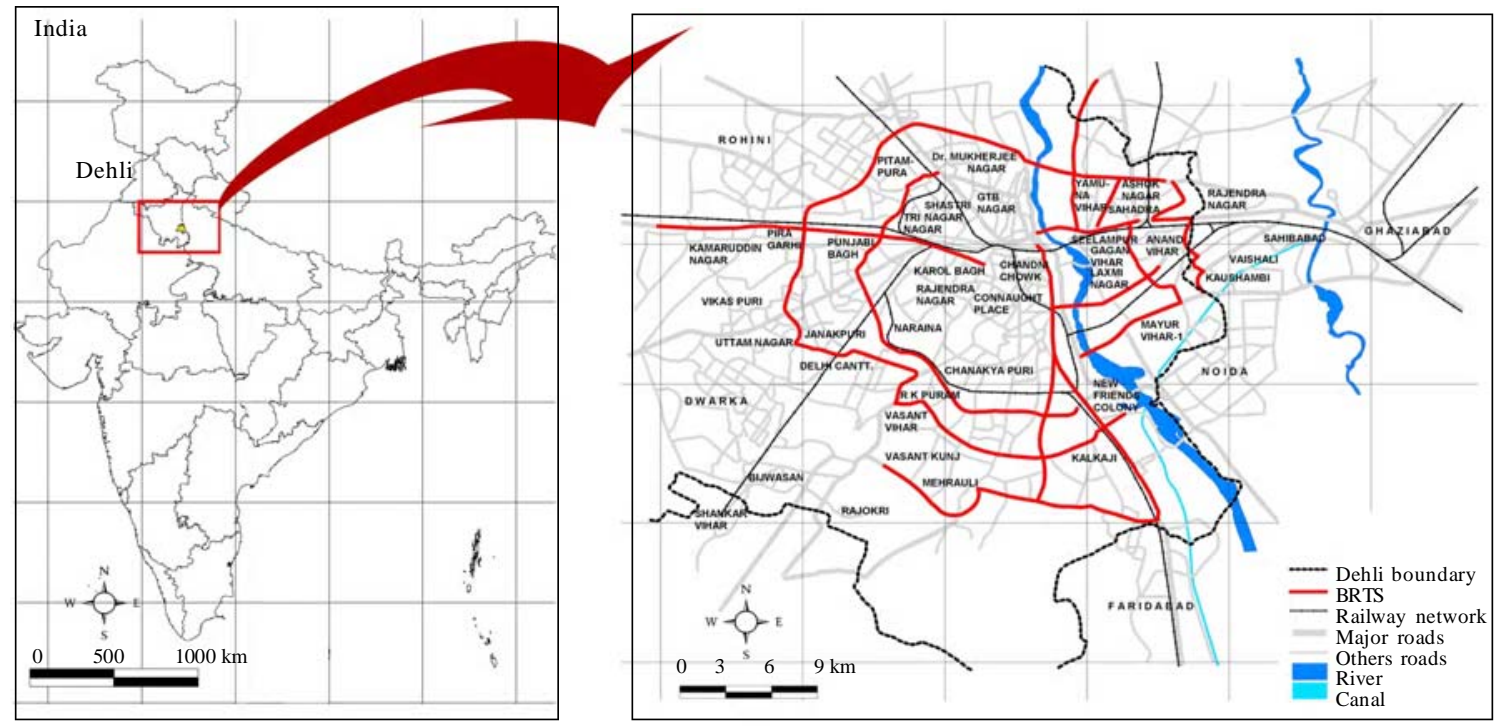

Fig. 1: Bus rapid transit system network of Delhi

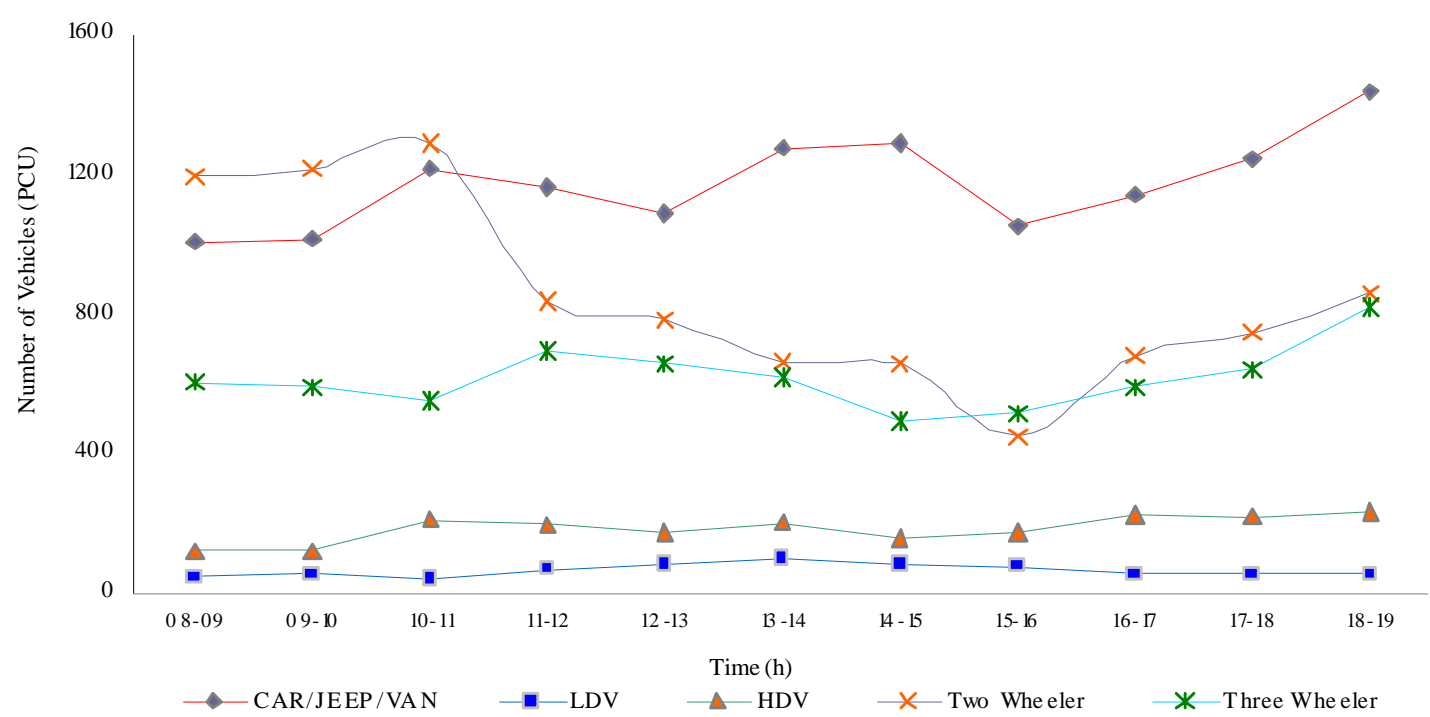

Fig. 2: Hourly traffic flow towards Moolchand at BRTS corridor

Data analysis and model development

The analysis is based on the application of FHWA (Federal Highway Administration) Model. This model has been utilised for the data analysis and in designing of noise barrier along the BRTS corridor. An acoustic barrier was designed on highway with particular reference to situation around the Red Fort, Agra (Nigam, 1996). A study was conducted at various locations of Delhi, Jaipur, Chandigarh, Allahabad and Lucknow and designed noise barrier at sensitive zones (Jain and Parida, 2004). Traffic noise levels in the vicinity of roadway can be predicted on the basis of individual vehicle noise levels, vehicle volume, speed, observer distance and other correlations. Traffic noise prediction algorithm is of the following form. The value Leq is determined from the following equation. 


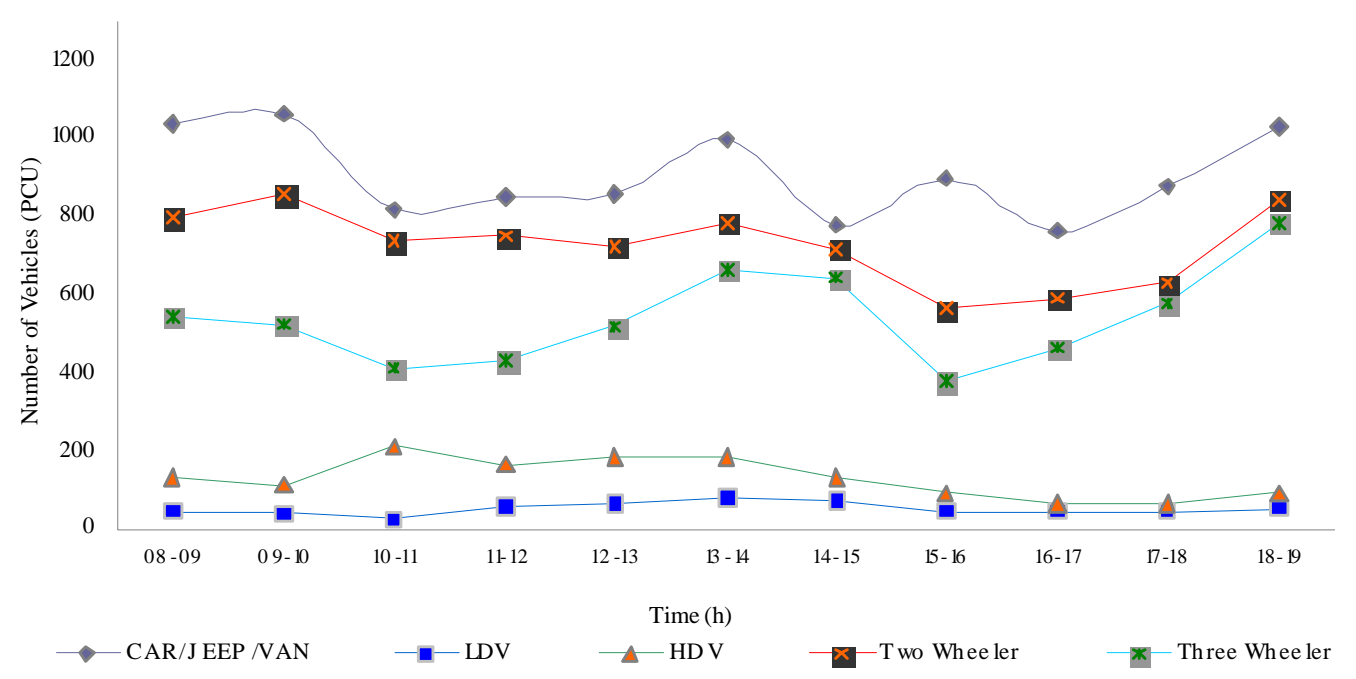

Fig. 3: Hourly traffic flow towards Ambedkar Nagar at BRTS corridor

Leq $=L_{0}+\Sigma L_{i}$

$\mathrm{L}_{0}=$ basic noise level for a stream of vehicles in dBA

$\mathrm{L}_{\mathrm{i}}=$ adjustment applied in dBA

Basic noise level is the noise emitted by a particular class of vehicle at a distance of $15 \mathrm{~m}$ from the center of the inner lane at a given speed and road surface. In this model vehicles have been divided into seven different categories as shown in Table 2.

Calculation of hourly Leq value has been done through developed spreadsheet (Fig. 4) during this research:

Combined noise level for each class of vehicle (i) and each roadway (j) is obtained from the following equation:

$L_{e q(i j)}=L_{0}+A_{v s(i j)}+A_{D i}+A g+A_{B}+A_{F}+A_{S}$

Where:

$\mathrm{L}_{\text {eq(ij) }}=$ Values are summed logarithmically to give equivalent noise due to traffic at the receiver

$\mathrm{L}_{0} \quad=$ Basic noise levels

$\mathrm{A}_{\mathrm{vs}(\mathrm{ij})}=$ Volume/speed (flow adjustment)

$\mathrm{A}_{\mathrm{Di}}=$ Distance adjustment

$A_{\mathrm{g}}=$ Ground adjustment

$\mathrm{A}_{\mathrm{B}(\mathrm{iij})}=$ Barrier adjustment

$A_{F}=$ Finite segment adjustment

$\mathrm{A}_{\mathrm{S}}=$ Shielding adjustment for buildings

Equivalent noise level due to traffic at the receiver will

$\begin{aligned} & \text { be: } \\ & L_{\text {eq }}\end{aligned}=10 \log \left(\sum_{i}^{n} 10^{\text {Leeij/10 }}\right)$
Where $\mathrm{n}$ is the number of roadways.

\section{RESULTS AND DISCUSSION}

Comparison of predicted and observed noise level

Barry and Reagan developed the Federal Highway Administration traffic noise prediction model (Anonymous, 1978) for the United State of America, Department of Transportation, Federal Highway administration. It calculates noise levels through a series of adjustments to a basic sound level, which is determined through field measurements of individual vehicles (Wilson, 1989). On the basis of the researcher's study it is conjectured that in this model the vehicles are adequately represented by acoustic point sources, emission levels within groups (automobile, medium and heavy trucks) are normally distributed and propagation losses are adequately represented by distance effects. Steele (2001) reviewed six traffic noise emission models i.e. FHWA highway traffic noise prediction model, FHWA traffic model version 1.0, CORTN model, RLS 90, MITHRA and StL-86 model. Within their range of validity, the models reviewed here meet the requirements of government regulations and many designers. Some models allow for other road vehicles as well as automobiles and trucks, and one includes car parks. All the models discussed here have acoustic energy descriptors usually explicit as Leq or in two cases as a pseudo- L10. The Leq models admit of easy corrections for interrupted flow, multiple streams and multiple roads. The six commonly used models reviewed 
Int. J. Environ. Sci. Tech., 7 (4), 737-750, Autumn 2010

Table 2: Basic noise level $\left(L_{0}\right)$ for identified vehicle categories (Jain and Parida, 2004)

\begin{tabular}{lcc}
\hline Category & Reference mean emission & Height of source $(\mathrm{m})$ \\
\hline Car/Jeep/Van & $\mathrm{L}_{0}=32.372 \log _{10}(\mathrm{~S})+15.891$ & 0.00 \\
Scooter/Motorcycle & $\mathrm{L}_{0}=35.871 \log _{10}(\mathrm{~S})+8.979$ & 0.00 \\
LCV/Mini Bus & $\mathrm{L}_{0}=31.212 \log _{10}(\mathrm{~S})+23.26$ & 0.70 \\
Buses & $\mathrm{L}_{0}=41.378 \log _{10}(\mathrm{~S})+8.873$ & 1.50 \\
Trucks & $\mathrm{L}_{0}=43.248 \log _{10}(\mathrm{~S})+6.597$ & 1.50 \\
Three-Wheeler & $\mathrm{L}_{0}=0.2202 \log _{10}(\mathrm{~S})+61.51$ & 0.00 \\
Tractor Trailor & $\mathrm{L}_{0}=6.4110 \log _{10}(\mathrm{~S})+73.065$ & 1.50 \\
\hline
\end{tabular}

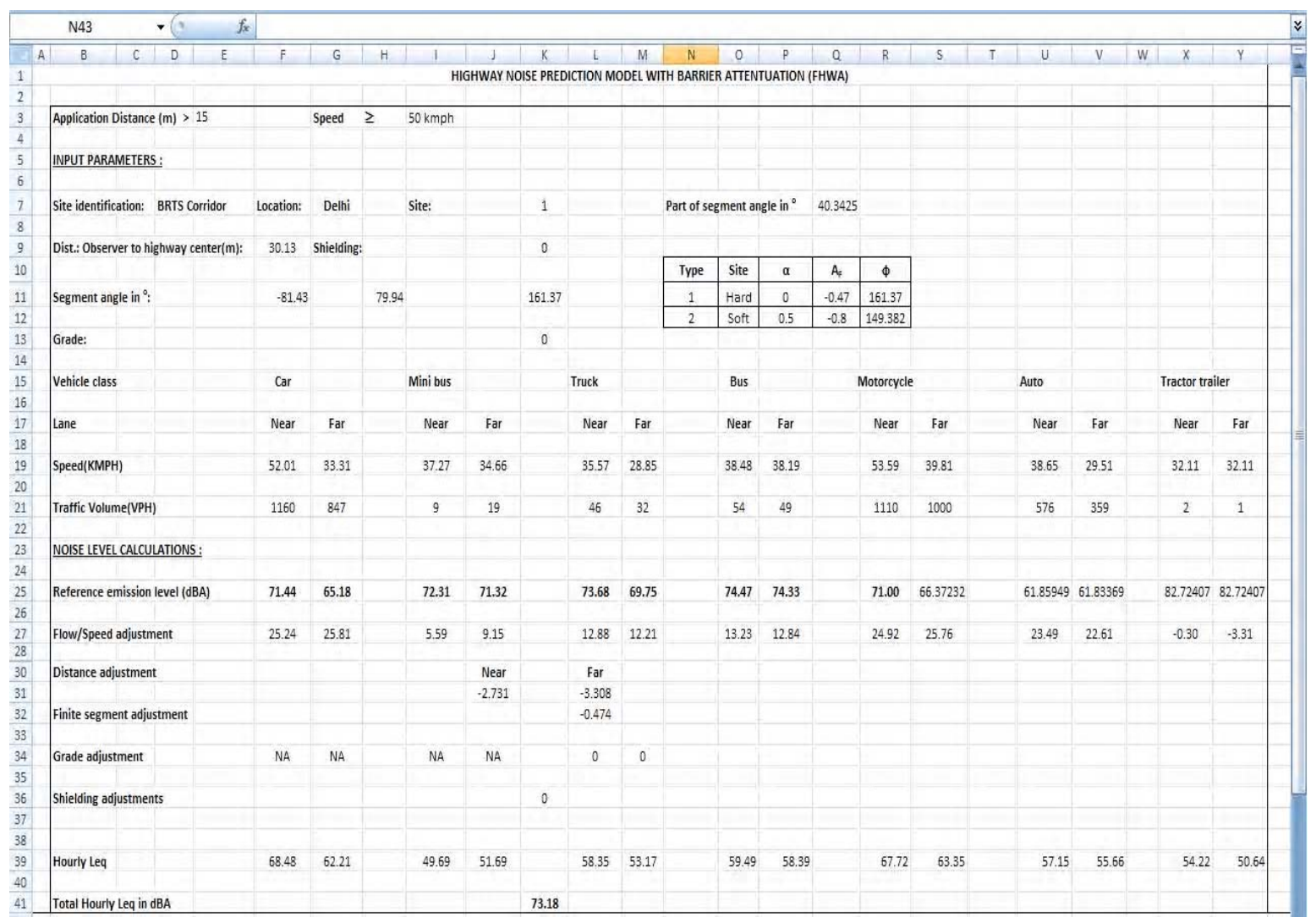

Fig.4: Print screen view of calculated noise level in developed excel sheet

here are designed to meet the requirements of roadway engineers primarily. They do not, however, meet the requirements of other users i.e. Architects, Acoustical experts etc. Kumar (2000) developed model foष, QaDd

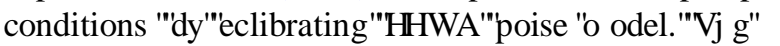
FHWA model calculates noise level through a series of adjustment to a reference sound level. These estimated Leq values, which has given $\mathrm{R}^{2}$ value of 0.793 . Thus, the equations for estimating the traffic noise levels for Indian conditions need to be calibrated model. Regression analysis has been used to get linear relationship between Leq values by 
FHWA model and those by calibrated model. A study had been conducted to develop a standard prediction model for noise pollution in Delhi, Jaipur, Allahabad, Chandigarh and Lucknow Cities of India. Noise modeling was carried out to examine the suitability of the FHWA and CORTN model along with regression based techniques and stastical analysis. Based on the study conducted in Delhi, Jaipur, Allahabad, Chandigarh and Lucknow city, the percentage variation between observed and predicted noise levels for FHWA ranges from 0.49 to $10.25,0.56$ to $10.25,0.42$ to $10.25,0.58$ to 12.25 and 0.75 to 10.78 respectively (Jain and Parida, 2004). On the basis of data analysis, following Figs. show the comparison of predicted and observed noise levels at both sides of bus rapid transit corridor. Fig. 5 indicates the highest predicted and observed value of noise level during 10:00 to 11:00 pm and 2:00 pm to 3:00 pm, respectively, whereas lowest predicted and observed noise value is found during single hour i.e. 4:00 pm to 5:00 pm. Similarly, Fig. 6 depicts the highest modeled (65.3 dBA) and monitored (78.9 dBA) value of noise level during 10:00 pm to 11:00 pm. While the lowest modeled (63.7 dBA) and monitored (66.9 dBA) value is found during 4:00 pm to 5:00 pm and 11:00 to 12:00 pm, respectively. From both the figures, it is found that the observed value is always higher than the predicted value during monitoring hours. Along with this the average percentage error between observed and predicted noise levels is found - 8.90 for FHWA model. Mostly all the existing traffic noise prediction models throughout the world are developed in and for western countries. In India, the traffic is heterogeneous in nature. Basic noise level equations need to be developed for the major vehicles plying in the traffic stream with a broad vehicle spectrum database. Current equations have been

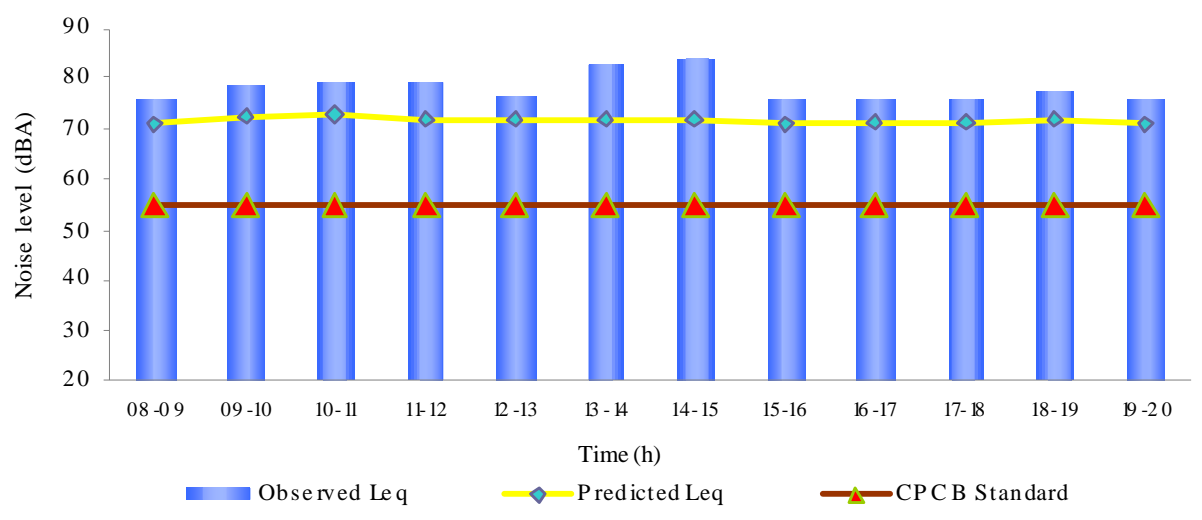

Fig.5: Comparison of predicted and observed noise levels at Moolchand BRTS corridor

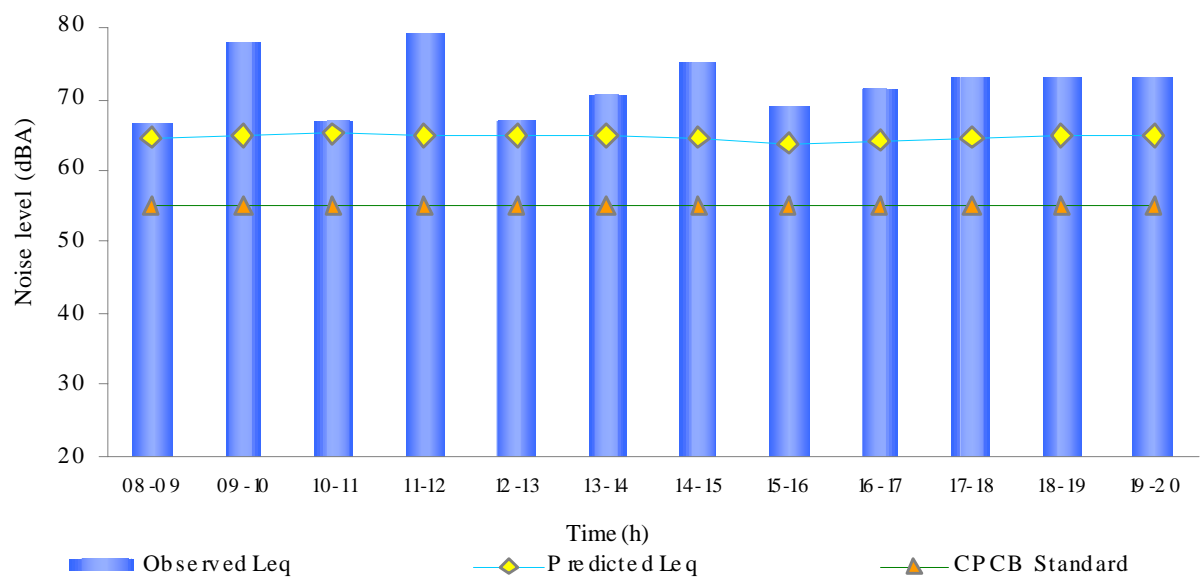

Fig. 6: Comparison of predicted and observed noise levels at Ambedkar Nagar BRTS corridor 
developed for limited data, which is a major constraint towards reducing the model prediction error.

\section{Effect of noise on human health}

From the observed data different value of noise level has been calculated. Fig. 7 shows the hourly variation of L10, L50, L90 and Leq noise levels. Maximum value of L10, L50, L90 and Leq is found during 13-14, 18-19, 18-19 and 14-15 h, respectively at Moolchand BRTS corridor. On the other hand, during 18-19 h, the highest value of L10, L50 and L90 is obtained but maximum Leq is found during 11-12 h at other location (Ambedkar Nagar) of BRTS corridor (Fig. 8). From both figures, it is found that the highest value of different types of noise levels are found mostly during peak hour of the day and the equivalent noise levels have been exceeded the ambient noise level prescribed by central pollution control board (CPCB). Due to rapid urbanization and the corresponding increase in the number of vehicles on Indian roads, the pollution is increasing at an alarming rate in most of Indian metropolitan cities. The noise levels are showing an alarming rise and in fact the levels exceed the prescribed levels in most of the areas. The ambient noise standards being followed in India for different types of areas are given in Table 3.

Noise emitted from traffic contributes about $55 \%$ of total noise pollution in India (The Hindu, 1997). Noise degrades the quality of life by affecting physical as well as mental status of person (Babisch, 2006). A number of acute and chronic effects on humans are found due to exposure to traffic noise (Koh and Jeyaratnam, 1998; Uimonen et al., 1998). It can cause disturbance in sleep, annoyance, mental disorders, hearing loss, and adverse physiological and psychological impacts (Miller, 1998). Agrawal and Swami, (2009) examined the problem of noise pollution in urban areas due to fast growing motor vehicles. To conduct the study, three hundred fifty individuals were interviewed. On the basis of his study, he developed a relationship between different noise parameters and its annoyance impact on exposed individuals using linear and multiple regression analysis. In this study the impact of noise on human health is made through the questionnaire based survey. The survey was conducted by face to face interview of residents and road users at BRTS corridor. The basic purpose of the survey was aimed to bring out the opinion of the residents about their health problems due to traffic noise. On the basis of this survey, it is found that $68 \%$ people reported the problem of stress due to traffic noise pollution. From the Fig. 9, it is clear that the problem of hearing damage has also been found a serious concern among people and has been reported by $64 \%$ people followed by the problem of blood pressure (56 \%), depression (48 \%), agitation (36\%) and fatigue (12\%).

\section{Design of noise barrier as an abatement measure}

The noise barrier has been designed taking into account of the land-use along the BRT corridor and

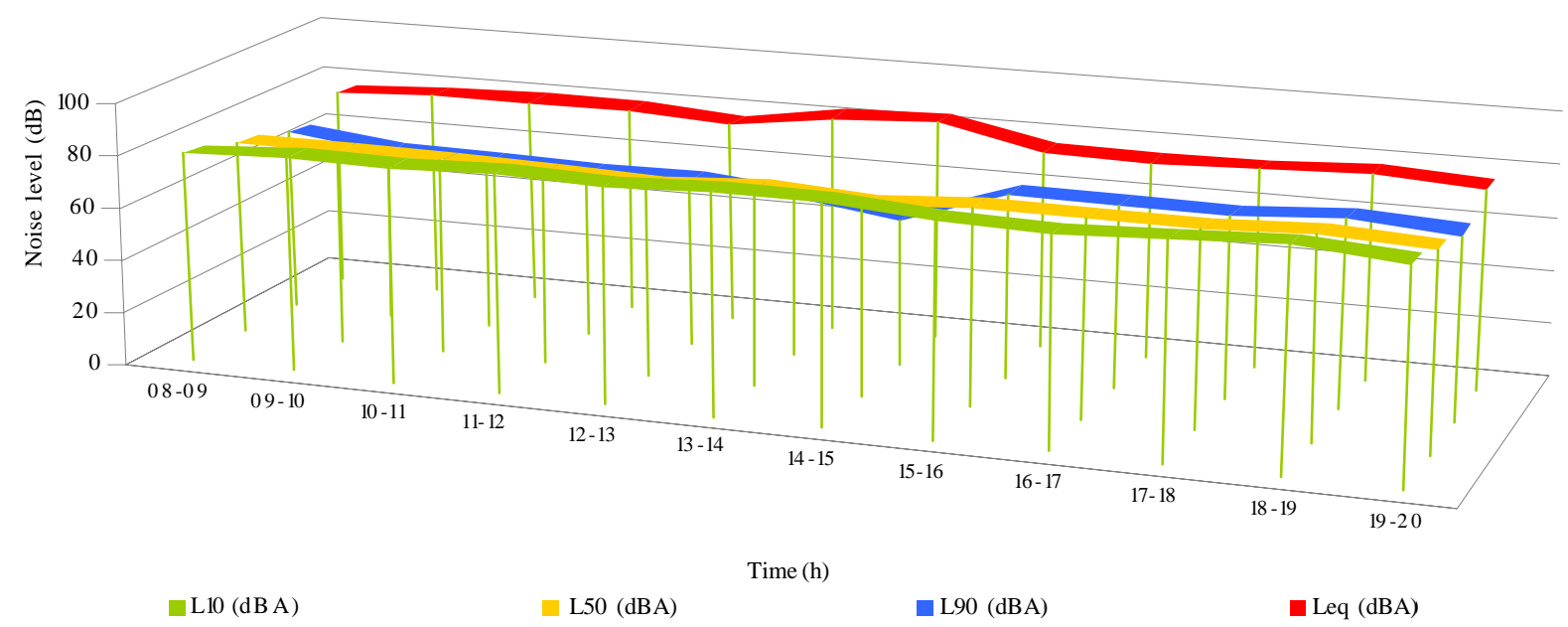

Fig. 7: Comparison of different observed noise level towards Moolchand at BRTS corridor 


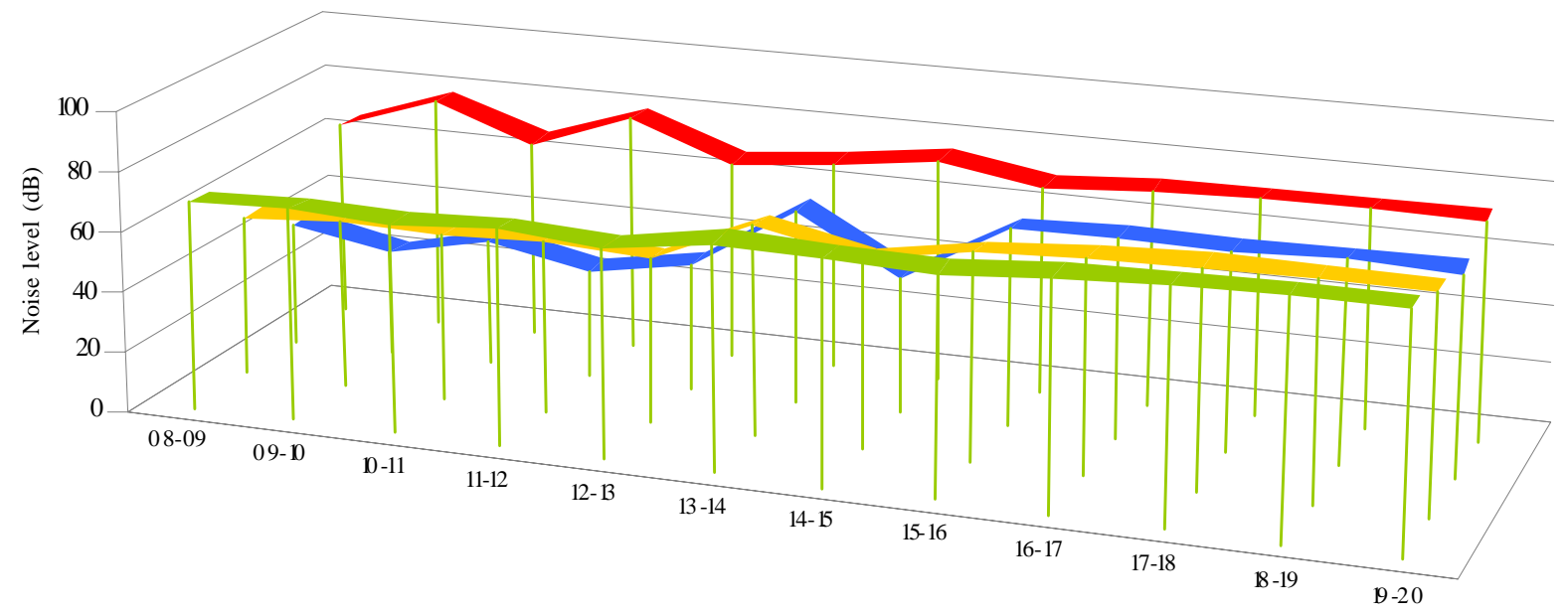

Time (h)
L10 (dBA)
L50(dBA)
L90 (dBA)
Leq (dBA)

Fig. 8: Comparison of different observed noise level towards Ambedkar Nagar at BRTS corridor

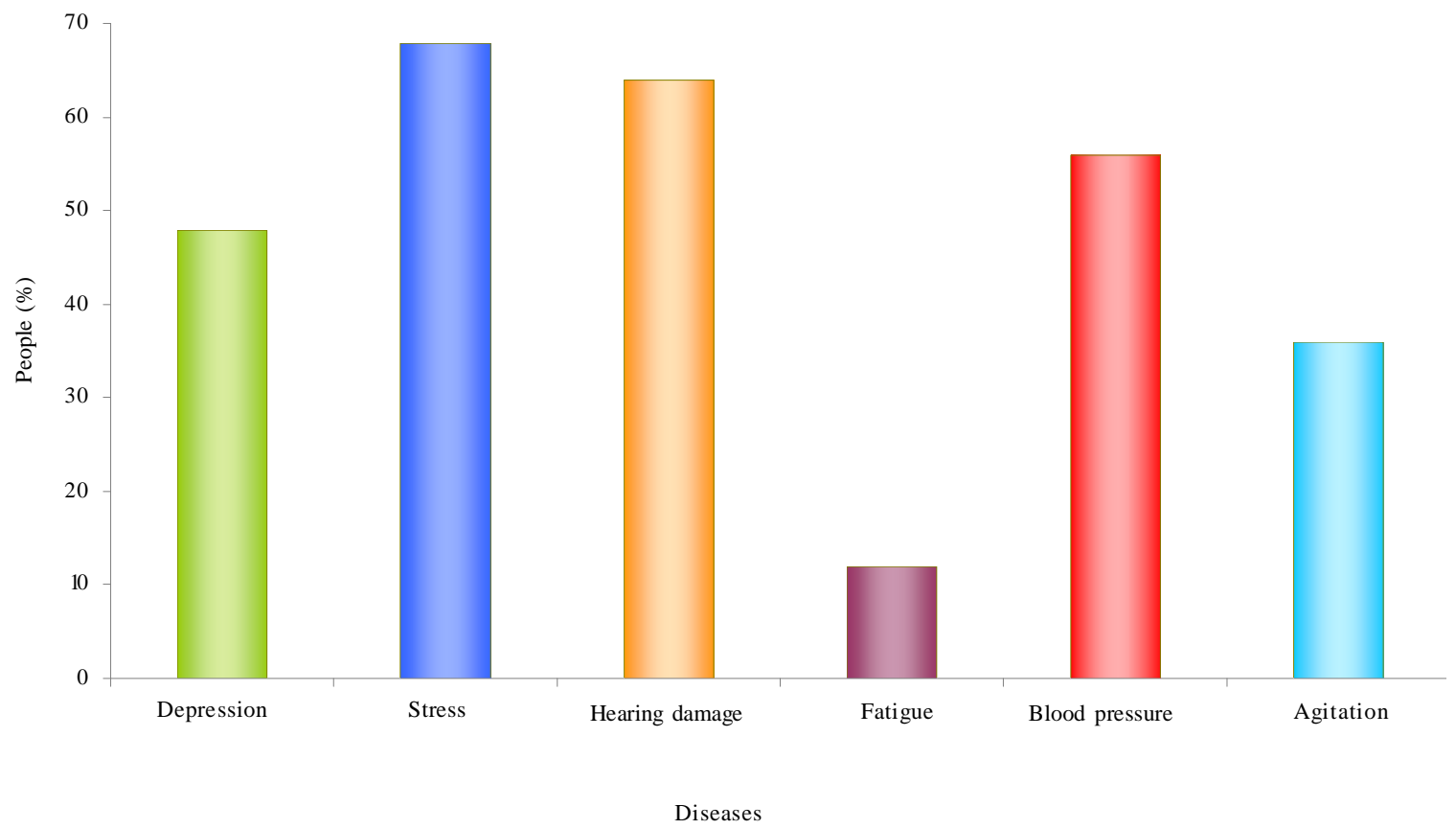

Fig. 9: Effects of noise on human health along BRTS corridor

Table 3: Ambient noise standards as per CPCB India

\begin{tabular}{lcc}
\hline Area & Day time Leq $(\mathrm{dB})$ & Night time Leq $(\mathrm{dB})$ \\
\hline Industrial area & 75 & 70 \\
Commercial area & 65 & 55 \\
Residential area & 55 & 45 \\
Silence zone & 50 & 40 \\
\hline
\end{tabular}




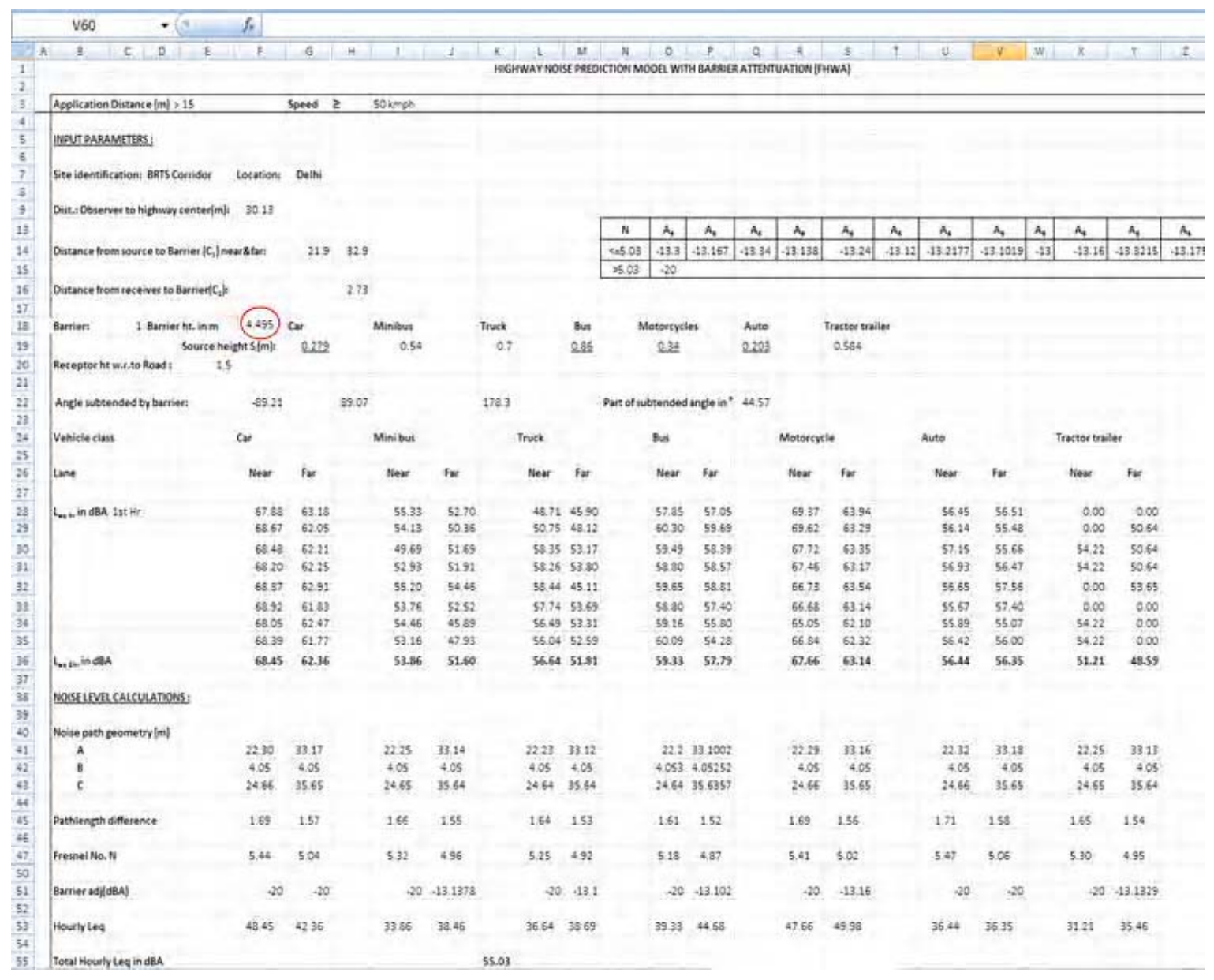

Fig.10: Print screen view of calculated barrier height in developed spread sheet

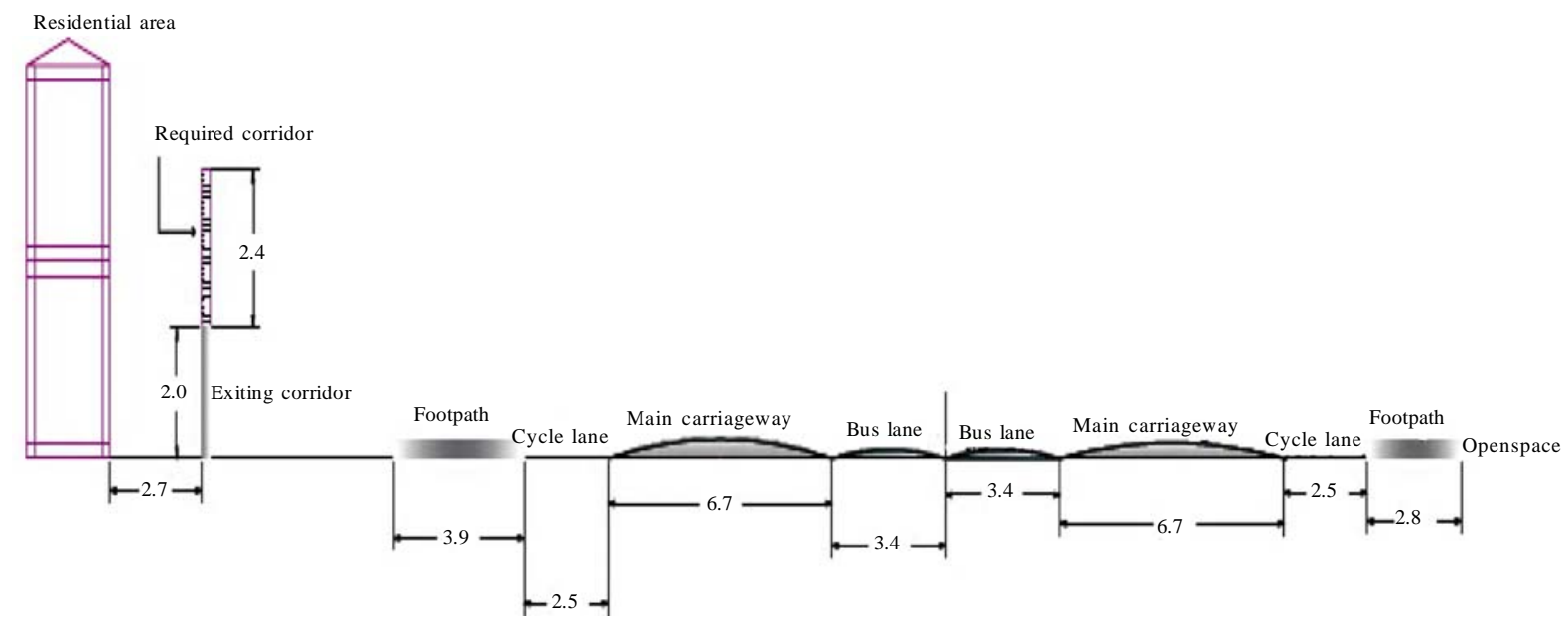

Fig. 11: Design of noise barrier at BRTS location (m) 


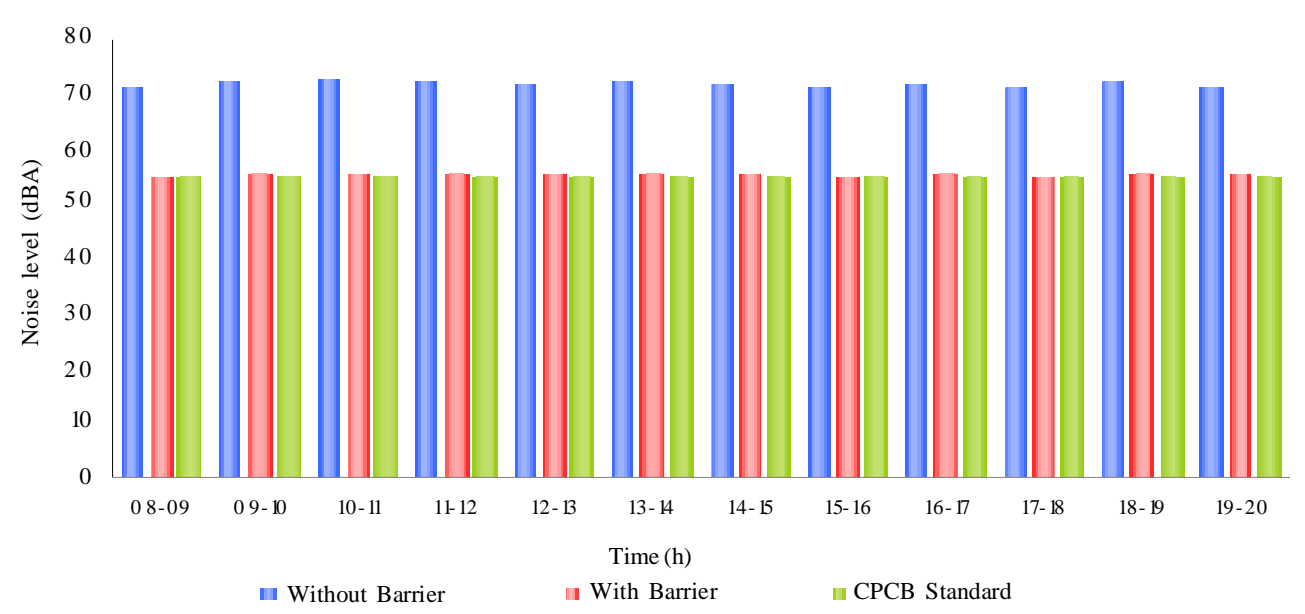

Fig. 12: Noise levels before and after the installation of suggested noise barrier at BRTS corridor

noise level generated from traffic. BRTS corridor has residential area on the one side (towards Moolchand) while open area on the other side. The analysis of data, as calculated in the excel sheet placed below (Fig. 10), for residential area of BRTS corridor, shows that there is a requirement of 4.4 meter height of the barrier. Two meter height of brick wall as barrier already exists near the residential area, on the road towards Moolchand. Calculation indicates the existing barrier height should be increased by $2.4 \mathrm{~m}$. On the other hand, due to the presence of open space (absence of residential or commercial area) there is no need to design noise barrier on the other side. Fig. 11 indicates the cross section and general layout of the BRTS corridor, with the designed noise barrier.

\section{Reduction in noise level after installation of barrier at BRTS corridor}

The study area at Panchsheel enclave, has three lane undivided carriage way that runs through Moolchand and Ambedkar nagar. This carriageway has high rise residential buildings on the one side and open area on the other side. Sensitive receivers identified are mainly on one side of the road. Noise barrier comprise of brick walls erected abutting residential buildings. Fig. 12 illustrates the existing noise level before and after the installation of noise barrier along residential side of BRTS corridor. While the designed noise barrier reduces noise level to the CPCB standard of $55 \mathrm{dBA}$, additional precautions need to be taken to reduce the noise levels at higher floors. They may need acoustic treatment of building façade, like applying sound absorbing materials on the external walls etc.
Various traffic mitigatory measures can also be implemented to reduce the noise pollution like landuse planning and control, improvement in roadway alignment and geometric design and further transportation system management (TSM) measures.

\section{CONCLUSION}

Based on this study, it is concluded that traffic noise caused by heavy traffic flow condition on the main BRTS corridor is significant and exceeding the national CPCB standards. This is alarming considering the fact that the traffic volume is going to increase further in coming years. Due to heavy traffic volume, traffic noise is also increasing at this particular corridor. In response to this, noise abatement measures have been proposed to curb the noise pollution in the vicinity of the concerned transport corridors. These measures mainly include construction of noise barriers and adopting traffic mitigatory measures. From the developed spread sheet, it is calculated that $2.4 \mathrm{~m}$ height of barrier is required to increase the height of brick wall as a barrier already existed there to reduce the noise level up to a permissible limit. A comprehensive program of public education and awareness is also the key for success and effectiveness of measures that would reduce urban traffic noise and protect the public from its unwanted impacts.

\section{ACKNOWLEDGEMENTS}

The authors would like to acknowledge the financial support of Ministry of Human Resource Development (MHRD), grant number MHR 02-13-200-429. The authors are also thankful to the assistance of Centre for Transportation Systems (CTRANS) and Department 
of Management Studies (DOMS), IIT Roorkee.

\section{REFERENCES}

Agrawal, S.; Swami, B. L., (2009). Road traffic noise annoyance in Jaipur city. Int. J. Eng. Stud., 1 (1), 39-46 (8 pages).

Anonymous, (1978). FHWA traffic noise prediction model US. Washington: Department of Transportation, Federal HighwayAdministration National Technical Information Service.

Babisch, W., (2006). Transportation noise and cardiovascular risk: Updated review and synthesis of epidemiological studies indicate that the evidence has increased. Noise Health., 8, 1-26 (26 pages).

Banerjee, D.; Chakraborty, S. K.; Bhattacharyya, S.; Gangopadhyay, A., (2009). Appraisal and mapping the spatial-temporal distribution of urban road traffic noise. Int. J. Environ. Sci. Tech., 6 (2), 325-335 (11 pages).

Banerjee, D., (2008). Study of precipitation chemistry over an industrial city. Int. J. Environ. Sci. Tech., 5 (3), 331-338 (8 pages).

Bengang, L.; Shu T.; Dawson, R. W., (2002). Evaluation and analysis of traffic noise from the main urban roads in Beijing. Appl. Acoust., 63 (10), 1137-1142 (6 pages).

Bengang L.; Shu T.; Dawson R. W.; Jun C.; Kinche L., (2002). A GIS based road traffic noise prediction model. Appl. Acoust., 63 (6), 679-691 (13 pages).

Beranek and Newman Inc., (1976). Highway noise. generation and control. NCHRP Report \# 173.

Bhattacharya, C. C.; Jain, S. S.; Singh. S. P.; Parida, M.; Namita, M., (2001). Development of comprehensive highway noise model for Indian conditions. Indian Road Congress., Paper No. 481.

Chung, E.; Bhaskar, A.; Kuwahara, M., (2007). Large area noise evaluation. in: Morrison, G. M.; Rauch, S., (Eds.), Highway and urban environment. Springer Netherland Publishing. Netherland.

Duran, A.; González, A., (2009). Determination of lead, naphthalene, phenanthrene, anthracene and pyrene in street dust. Int. J. Environ. Sci. Tech., 6 (4), 663-670 (8 pages).

Gupta, A., (1979). Relationship between vehicles noise and stream flow parameters. M. E. dissertation, University of Roorkee, India.

Gupta, A. K.; Nigam, S. F.; Hansi, J. S., (1986). A study on traffic noise for various land use for mixed traffic flow. Indian Highways., 14 (2), 30-47 (18 pages).

Jain, S. S.; Parida, M., (2004). Urban transport environment interaction. AICTE Nationally coordinated project final report submitted to AICTE, New Delhi, India.

Jetti, Y., (2003). Performance evaluation of noise prediction model. M. E. dissertation, Indian Institute of Technology, Roorkee, India.

Jha, M. K.; M. W. Kang, (2009). GIS-based model for highway noise analysis. J. Infrastructure Sys, 15 (2), 88-94 (7 pages).

Joel, M. A.; F. A. Lenzi; P. H. T. Zannin, (2004). Effects of traffic composition on road noise: A case study. Transport. Res. Part D., 9 (1), 75-80 (6 pages).
Johnson, D. R.; Saunders, E. G., (1968). The evaluation of noise from freely flowing road traffic. J. Sound Vib., 7 (2), 287-309 (23 pages).

Klæboe R.; Amundsen, A. H.; Fyhri, A.; Solberg, S., (2004). Road traffic noise-the relationship between noise exposure and noise annoyance in Norway. Appl. Acoust., 65 (9), 893-912 (20 pages).

Koh, D.; Jeyaratnam, J., (1998). Occupational health in Singapore. Int. Arc. Occup. Environ. Health, 71 (5), 295301 (7 pages).

Kumar, P., (2000). Traffic noise prediction for rural highways, M. E. Dissertation. University of Roorkee, India.

Kumar, V., (1997). Analysis of urban traffic noise. M. E. Dissertation, University of Roorkee, India.

Langdon, F. J.; Scholes, W. E., (1968). The traffic noise index-a method of assessing noise nuisance. Archit. J., 813820 (8 pages).

Lebiedowska, B., (2005). Acoustic background and transport noise in urbanized areas: A note on the relative classification of the city soundscape. Transport. Res. D-TR Environ., 10 (4), 341-345 (5 pages).

Miller, G. T., (1998). Living in the Environment, $10^{\text {th. }}$ (Ed.) Wadsworth, New York.

Mohammadi Roozbahani, M.; Nassiri, P.; Jafari Shalkouhi, P., (2009). Risk assessment of workers exposed to noise pollution in a textile plant. Int. J. Environ. Sci. Tech., 6 (4), 591-596 (6 pages).

Nelson, P. M.; Godfrey, N., (1974). Predicting road traffic noise in the rural environment. TRRL Laboratory Report 642, Berkshire.

Nelson, P. M.; Piner, P. M,. (1977). Classifying road vehicles for the prediction of road traffic noise. TRRL Laboratory Report 752, Berkshire.

Nigam, S. P., (1996). Design of an acoustic barrier for highway noise control. Indo-US Symposium on Emerging Trends in Vibration in Noise Engineering., 151-160.

Office of the Registrar General of India, (2001). Rural-urban distribution of population in The Census of India. New Delhi, India. Available at: http://www.censusindia.net/ results/rudist.html.

Omidvari, M.; Nouri, J., (2009). Effects of noise pollution on traffic policemen. Int. J. Environ. Res., 3 (4), 645-652 (8 pages).

Padam, S.; S. K. Singh, (2001). Urbanization and urban transport in India: The sketch for a policy, transport asia project workshop, Pune, India. Available at: http:// www.deas.harvard.edu/TransportAsia/workshop_papers/ Padam-Singh.pdf.

Phan, H. Y. T.; Yano, T.; Phan, H. A. T.; Nishimura, T.; Sato, T.; Hashimoto, Y., (2010). Community responses to road traffic noise in Hanoi and Ho Chi Minh City. Appl. Acoust., 71 (2), 107-114 (8 pages).

Pamanikabud, P.; Tansatcha, M., (2003). Geographical information system for traffic noise analysis and forecasting with the appearance of barriers. Environ. Model. Softw., 18 (10), 959-973 (15 pages).

Pamanikabud, P.; Vivitjinda, P. (2002). Noise prediction for highways in Thailand. Transport. Res. D-TR. Environ. 7 (6), 441-449 (9 pages). 
Samuels, S. E.; Thomas, C. D. L., (1978). The measurement and analysis of road noise. Australian Road Research Board., Internal Report AIR 258-1.

Sarin, S. M., (1990). Evaluation of road traffic noise problem at scientist apartment in Delhi. A Report, Environmental and Road safety Division Central Road Research institute (CRRI) New Delhi, India.

Scholes, W. E.; Sargent, J. W., (1971). Desigining against noise from road traffic. Appl. Acoust., 4 (3), 203-234 (32 pages).

Sharma, A.; Vijay, R.; Sandar, V. K.; Sohony, R. A.; Gupta, A., (2010). Development of noise simulation model for stationary and mobile sources: A GIS-based approach. Environ. Model. Assess., 15 (3), 189-197 (9 pages).

Sheikh, S., S., (2002). Development of a noise prediction model for Indian traffic conditions on a national highway. M.Tech Dissertation, Indian Institute of Technology, Roorkee, India.

Steele, C., (2001). A critical review of some traffic noise prediction models. Appl. Acoust., 62 (3), 271-287 (17 pages).

Tang, U. W.; Wang Z. S., (2007). Influences of urban forms on traffic-induced noise and air pollution: Results from a modelling system. Environ. Model. Softw., 22 (12), 17501764 (15 pages).

The Hindu, (1997). Survey on environment-97. A report published by The Hindu (National News Paper), New Delhi, India.

Uimonen, S.; Maki-Torkko, E.; Sorri, M., (1998). Hearing and occupation. Int. J. Circumpolar Health, 57 (2-3), 156161 (6 pages).

Unweltbundesamt, L., (2000). Report of the German Environmental Agency, Berlin.

William, H. K. L.; Tam M. L., (1998). Reliability analysis of traffic noise estimates in Hong Kong. Transport. Res. DTR. Environ., 3 (4), 239-248 (10 pages).

Wilson, (1989). Noise control. Harper and Row Publishers, New York.

Yognarayana, K.; Ramalingeswara, R. P., (1994). Noise monitoring at Ramagundam area. Indian J. Environ. Protect., 14 (12), 915-920 (6 pages).

Zannin, P. H. T.; Calixto, A.; Diniz, F. B.; Ferreira, J. A. C., (2003). A survey of urban noise annoyance in a large Brazilian city: The importance of a subjective analysis in conjunction with an objective analysis. Environ. Impact Asses., 23 (2), 245-255 (11 pages).

\section{AUTHOR (S) BIOSKETCHES}

Mishra, R. K., Ph.D. Scholar, Center for Transportation Systems (CTRANS), Indian Institute of Technology (IIT), Roorkee, India.

Email: rajeevmishraiitr@gmail.com

Parida, M., Ph.D., Professor, Civil Engineering Department and Associated Faculty, Center for Transportation Systems (CTRANS), Indian Institute of Technology (IIT), Roorkee, India. Email: mparida@gmail.com

Rangnekar, S., Ph.D., Associate Professor, Department of Management Studies, Indian Institute of Technology (IIT), Roorkee, India. Email: srangnekar1@gmail.com

How to cite this article: (Harvard style)

Mishra, R. K.; Parida, M.; Rangnekar, S., (2010). Evaluation and analysis of traffic noise along bus rapid transit system corridor. Int. J. Environ. Sci. Tech., 7 (4), 737-750. 